\title{
Graduating nurses face a new reality
}

By Dada L. Kring, RN,BC, MSN, Barbara J. Mueller, RN, MSN, and Susan Letvak, RN, PHD

Kring, D., Mueller, B., \& Letvak, S. (2008). Graduating nurses face a new reality. Men in Nursing, 3(2), 22-26.

Made available courtesy of Lippincott, Williams \& Wilkins: http://www.lww.com/men-innursing-journal.html

\section{***Note: Figures may be missing from this format of the document}

The "reality shock" phase may be getting longer for new graduate nurses who need manageable workloads and adequate help to feel satisfied.

Nursing job satisfaction has become exceedingly important in organizations in light of the continual struggle to keep nursing positions filled. The nursing shortage, which drives the struggle, is recognized as a critical problem by the American Nurses Association, the American Hospital Association, The Joint Commission, and the Nursing Executive Center. ${ }^{1-4}$ Buerhaus found that nurses are aging out of the profession and are not being replaced by younger generations at the same rate. ${ }^{5}$ Preliminary data from the 2004 National Sample Survey of Registered Nurses documents the average age of an RN is now 46.8 years. ${ }^{6}$ Buerhaus projects that by 2020, with the retirement of the largest cohort of nurses and the medical needs of the baby boomers, the RN workforce will be $20 \%$ below the projected requirement. ${ }^{5}$ This aging is creating a vast number of open, unfilled nursing positions. These open positions are most keenly felt in the acute care settings. As the RNs leave the workforce, there must be a steady influx of new nurses to take positions left by those retiring. Each year most hospitals hire many new graduate nurses to fill vacancies that have sat empty for months. The challenge for organizations is to keep these new nurses at the bedside once they're there. The vacancies left by retiring nurses are compounded by the resignations and transfers of new nurses shortly after they're hired. Organizations must work to retain these new RN employees and respond to issues that interfere with their job satisfaction.

During the first year of employment, most new graduate nurses report dissatisfaction with their jobs, and many leave their positions. ${ }^{7}$ Kramer's work, done in the 1970 's, labeled what these new graduates were experiencing as "reality shock. ${ }^{8} \mathrm{New}$ graduates, transitioning from school to employment, found a disconnect from what they expected nursing to be and what they actually experienced. Kramer's qualitative research revealed that the new graduate goes through four distinct phases: honeymoon, shock, recovery, and resolution. If the conflict of the shock phase is never resolved, nurses may leave the profession all together. While Kramer's framework suggests a typical linear progression of new graduate practice, no timeframe has been studied that delineates when the transitions will likely take place.

\section{Our questions}


We wanted to describe the job satisfaction of new graduate nurses at 3, 6, 9, and 12 months of employment. We expected nurses to follow a pattern similar to Kramer's conceptual framework. From our personal experiences with new graduate nurses, we have seen that at the 3- month point new nurses are in a honeymoon phase and satisfied with their first nursing job. By 6 months, reality shock hits and satisfaction plummets. By 9 months, the dissatisfaction is beginning to wane as coping strategies are incorporated into daily routines. By 12 months, the new nurse has resolved most internal conflicts and is beginning to thrive under a revised concept of safe nursing practice and experiencing again a high level of satisfaction. We wanted to know:

- How satisfied are nurses during their first year of employment?

- Does the level of satisfaction change at different points during the first year of employment?

New graduate nurses from a large five-campus community health system completed a staff satisfaction survey mailed directly to their homes at 3 months, 6 months, 9 months, and 12 months of employment. A total of 97 surveys over the course of the year were returned. Most nurses worked either day or night shift in either medical-surgical departments or intensive care departments. (See "Research box.")

\section{Research Box}

Purpose: To describe the job satisfaction of new graduate nurses at 3, 6, 9, and 12 months of employment.

Location: A large five-campus community health system in the southeastern United States. Population: All new graduate nurses who began employment during a 1 year time period $(\mathrm{N}=101)$.

Timeframe: Participants were followed for 1 year.

Collection tool: The staff satisfaction survey was administered at 3, 6, 9, and 12 months of employment.

Sample Size: Twenty-six percent $(\mathrm{N}=26)$ returned their 3-month survey, 29\% $(\mathrm{N}=29)$ returned their 6- month survey, 25\% ( $\mathrm{N}=25)$ returned their 9-month survey, and 17\% ( $\mathrm{N}=17)$ returned their 12-month survey, for a total of 97 surveys over the course of the data collection period. Findings: Satisfaction didn't vary significantly over the course of the year. New graduate nurses are moderately satisfied but don't plan on staying in their current setting for more than 1.5 years.

\section{Study findings}

This study didn't show typical reality shock progression within the first year. For the 12 months that these nurses were followed, no predictable pattern was revealed. The overall satisfaction throughout the year hovered around 6 to 7 for the 10-point scaled question (10 equals totally satisfied). Although not statistically significant, most items showed a decline in mean satisfaction from 3 months to 12 months with variability in the 6- and 9- month points. With the intensely complex work environments of modern acute care hospitals, nurses may have a more difficult and lengthy transition period from school to work. This transition time may be longer than nurses experienced a decade ago, thus lengthening the reality shock phase. With a lesser sense of perceived competence after 1 year than earlier generations, nursing orientation models may need to be modified to accommodate the longer transition time. Another explanation may be that most nurses, regardless of years of experience, are caught up in stressful work environments that 
hospitals are struggling to control. The complexity of modern healthcare may have made it difficult for bedside nurses to find a high level of satisfaction.

No matter how satisfied or dissatisfied respondents were with their job, they didn't plan on staying more than 1.5 years in their current setting. This finding is in opposition to earlier research and may point to generational preferences of 20- and 30-year-olds who do not demonstrate corporate loyalty like the baby boomer generation, even if they are satisfied with their job. In fact, the question asking how long they plan on staying in their current position was the only question that had absolutely no significant correlations with any of the other job satisfaction questions on the survey. This finding may be disheartening for nurse administrators that view high retention rates as a measure of leadership competence and organizational achievement.

Many hopeful responses emerged from the data. Overall, nurses were proud to be nurses. This was the highest rated question on the survey. At 3 months the average response was 4.6 (on a 5point scale), and had only dropped to 4.5 by 12 months. This finding hopefully suggests that dissatisfied nurses will not leave the profession, but strive to improve workplace environments or find their niche in other healthcare settings. Another positive finding was that new nurses received help on their departments and their coworkers were responsive to their questions. Even in very busy hospital departments, the perception by new nurses was one of support and teamwork. In addition, a significant correlation existed between nurses who received help on their departments and their overall satisfaction. During the current nursing shortage, "eating our young" is an orientation practice that will not allow inpatient nursing to survive. These results support a turn toward a more caring, welcoming culture.

Several other correlations stood out among the data as significant. When nurses' workloads were manageable, their overall satisfaction was high. Nursing workloads are physically demanding, as well as intellectually intense. The introduction of computerized documentation, wireless phones, and other technological advances have added complexity and stress to the bedside nursing role. Mandating ratios, engineering nurse-friendly units, and implementing flexible and diverse work schedules to cover periods of high activity have been priority strategies for hospital administrators in an attempt to ease this nursing workload. The findings from this study support such efforts. Clearly, new nurses are more satisfied when they perceive their workloads as manageable.

In addition, the higher the overall satisfaction with their current job, the less burned out new nurses felt. This relationship seems obvious, but it is important to note that new nurses understand the concept of burnout, and indeed, some had already experienced it.

Four questions fell out as having the most significant correlations with other aspects of job satisfaction. It may be possible to determine the satisfaction of new graduates by asking only these four questions, and especially the first item, which correlated significantly with all others except one. These four questions involve overall satisfaction with current position, feeling valued as an employee, strong departmental communication, and receiving help when needed. 
For this study, four questions also stood out as having little correlation with other questions in the survey, suggesting that they didn't have much impact on satisfaction levels. These items included how long one planned on staying in his/her current position, worrying about work injury, satisfaction with benefits, and overtime requirements.

\section{Future recommendations}

New nurses need many supports in place to be successful in the intensely complex acute care environment. These supports are often placed early in the nurse's orientation, but may dwindle over the course of the year. Providing orientation models that last throughout the year, perhaps longer, may improve satisfaction. Such models may include monthly new graduate seminars and continuing education with paid time off, monthly meetings between new graduates, their preceptors, and department directors to discuss potential issues, and new graduate discussion groups led by an experienced nurse leader. In addition, new graduates need to be allowed to practice as novices and advanced beginners for their first year. This may include protecting their assignments to a reasonable acuity level and providing shift-based clinical experts to assist with complex patient situations.

Nursing directors shouldn't necessarily be penalized for high new graduate turnover rates. Rather, programs should be put in to place that will allow nurses to transfer to other departments easily. Some innovative hospitals are even allowing nurses to try out a new department before making a commitment to transfer and have hired retention coordinators to provide career counseling for dissatisfied nurses. These programs recognize that new nurses will not make a long-term commitment to one department so early in their nursing career.

Hospital organizations should capitalize on nurse pride. Hospital recognition programs, including nursing awards, as well as individual recognition from colleagues and supervisors in the form of thank you notes and 


\begin{tabular}{|c|c|c|c|c|c|}
\hline & 3 months & 6 months & 9 months & 12 months & Total \\
\hline$N=$ & 26 & 29 & 25 & 17 & 97 \\
\hline Age $M(S D)$ & $32(10.3)$ & $29.9(10)$ & $28.5(8.1)$ & $32(11.3)$ & $30.4(9.7)$ \\
\hline Nursing degree $\mathrm{N}(\%)$ & $\begin{array}{l}\text { BSN-11 }(44 \%) \\
\text { ADN-14 }(56 \%) \\
\text { Diploma-0 }\end{array}$ & $\begin{array}{l}\text { BSN-11 }(41 \%) \\
\text { ADN-16 }(59 \%) \\
\text { Diploma-0 }\end{array}$ & $\begin{array}{l}\text { BSN-10 }(42 \%) \\
\text { ADN-14 }(58 \%) \\
\text { Diploma-0 }\end{array}$ & $\begin{array}{l}\text { BSN-5 }(29 \%) \\
\text { ADN-11 }(65 \%) \\
\text { Diploma }-1(6 \%)\end{array}$ & $\begin{array}{l}\text { BSN-37 }(40 \%) \\
\text { ADN-55 }(59 \%) \\
\text { Diploma-1 } 1(1 \%)\end{array}$ \\
\hline $\begin{array}{l}\text { Employment status } \\
\mathrm{N}(\%)\end{array}$ & $\begin{array}{l}\text { Fulltime- } \\
26(100 \%)\end{array}$ & $\begin{array}{l}\text { Fulltime- } \\
28(100 \%)\end{array}$ & $\begin{array}{l}\text { Fulltime- } \\
24(100 \%)\end{array}$ & $\begin{array}{l}\text { Fulltime- } \\
17(100 \%)\end{array}$ & $\begin{array}{l}\text { Fulltime- } \\
95(100 \%)\end{array}$ \\
\hline Day shift $N(\%)$ & $10(38 \%)$ & $10(34 \%)$ & $7(28 \%)$ & $7(41 \%)$ & $34(35 \%)$ \\
\hline Evening shift & $1(4 \%)$ & $1(3 \%)$ & $3(12 \%)$ & 0 & $5(5 \%)$ \\
\hline Night shift N (\%) & $7(27 \%)$ & $12(41 \%)$ & $9(36 \%)$ & $7(41 \%)$ & $35(36 \%)$ \\
\hline Rotating shifts $\mathrm{N}(\%)$ & $8(31 \%)$ & $6(21 \%)$ & $6(24 \%)$ & $3(18 \%)$ & $23(24 \%)$ \\
\hline Med-surg N (\%) & $12(46 \%)$ & $8(28 \%)$ & $9(36 \%)$ & $8(47 \%)$ & $37(38 \%)$ \\
\hline Intensive care unit $\mathrm{N}(\%)$ & $7(27 \%)$ & $12(41 \%)$ & $7(28 \%)$ & $5(29 \%)$ & $31(32 \%)$ \\
\hline Procedural N(\%) & $2(8 \%)$ & $4(4 \%)$ & $3(12 \%)$ & $1(6 \%)$ & $9(9 \%)$ \\
\hline Other area $\mathrm{N}(\%)$ & $4(15 \%)$ & $5(17 \%)$ & $6(24 \%)$ & $3(18 \%)$ & $18(19 \%)$ \\
\hline
\end{tabular}

announcements of achievements will keep nursing pride high. In addition, a professionally designed and published nursing newsletter that highlights nurses' accomplishments and features stories on quality initiatives and patient successes supports a positive nursing culture. Encouraging other professional activities, such as shared governance models, research initiatives, and national conference presentations, will also foster pride and satisfaction in nursing.

New graduate nurses are proud of their profession. However, they experience many stressors during their first nursing job. Determining ways of measuring their satisfaction levels may help organizations design strategies for supporting this group. Clearly, new graduate nurses need support during their entire first year, and perhaps long after. Colleague assistance and manageable workloads are the foundation of this support. They also want to feel valued as employees and perceive positive communication patterns in their departments.

\section{References}

1. American Nurses Association. Nursing's Agenda for the Future: A Cafl to the Nation. Aprif 2002. Availabfe at: http://nursingworfd.org/ forms/free/nursing Jpage5agenda.pdf. Accessed March 19, 2008.

2. American Hospitaf Association. The Hospitaf Workforce Short age: Immediate and Future. June 2001. Available at: http:// www.hospitafconnect.com/ahapolicyforum/trendwatch/twjune20 01.htmf. Accessed March 19, 2008.

3.The Joint Commission. Healthcare at the Crossroads: Strategies for Addressing the Evofving Nursing Crisis. September 2005. Available at: 
http://www.jointcommission.org/NR/rdonfyres/ 5C138711-ED76-4D6F-909FB06E0309F36D/0/health_care_at the_crossroads.pdf. Accessed March 19, 2008.

4. Nursing Executive Center. Nursing's Next Generation: Best Practices for Attracting, Training, and Retaining New Graduates. Washington, D.C.:The Advisory Board Company; 2002.

5. Buerhaus PI, Staiger DO, Auerbach DI. Impfications of an aging Registered Nurse workforce. JAMA: 2000;283:2948-2954.

6.US Department of Heafth and Human Services. The Registered Nurse Popufation: Nationaf Sample Survey of Registered Nurses. March 2004. Availabfe at: http://bhprhrsa.gov/healthworkforce/reports/rnpopufation/prefiminaryfindings.htm. Accessed March 19, 2008.

7.McCfoskey JC, McCain BE. Satisfaction, commitment and professionafism of newfy employed nurses. Image J Nurs Scb: 1987;19(1):20-24.

8. Kramer, M. Reality Shock: Why Nurses Leave Nursing. St. Louis: Mosby; 1974. 